African American Student Organizations 1

African American Student Organizations As Agents of Social Integration

Douglas A. Guiffrida

University of Rochester

2006 


\title{
African American Student Organizations As Agents of Social Integration
}

\begin{abstract}
In this qualitative study, 88 African American undergraduates were interviewed to understand the role of African American student organizations in facilitating social integration at a predominantly White institution. The conditions under which participation in these organizations aided students’ social integration are presented. Results largely support Tinto’s (1993) theory of student departure but indicate limitations of the theory when applying it to African Americans from predominantly White home communities.
\end{abstract}

African American college student retention rates at predominantly White institutions (PWIs) are well below those of White students at PWIs and African American students who attend historically Black colleges and universities (Astin, 1996; Benson, 1996; Patterson Research Institute College Fund/UNCF, 1997). According to Tinto’s (1993) theory of student departure, which has been described as one of the most comprehensive and validated models of college retention (Boyle, 1989; Gillespie \& Noble, 1992;

Pascarella \& Terenzini, 1991), college attrition can be attributed largely to a lack of fit between the student and the institution. In his theory, Tinto maintained that college students who perceive their norms, values, and ideas as congruent with those at the center of the institution are more likely to become academically and socially integrated into the college. Those who perceive incongruence between themselves and the institution will experience more difficulty becoming integrated and, therefore, are less likely to persist. 
Although academic and social integration are interrelated, he distinguished academic integration as relating primarily to the formal education of students. Social integration, on the other hand, focuses on students' personal affiliations with peers, faculty, and staff that occur largely outside the academic realm of the institution. Tinto proposed that, to varying degrees, some form of both academic and social integration were necessary for retention.

Tinto (1993) believed that African American students face unique challenges to becoming academically and socially integrated into PWIs because their norms and values may be incongruent with those of the White majority. Because research has indicated that African American students are often less academically prepared than their White peers (Allen, 1988; Cabrera, Nora, Terenzini, Pascarella, \& Hagedorn, 1999; Donovan, 1984; Loo \& Rolison, 1986; Nettles, Thoeny, \& Gosman, 1986; Nora, Cabrera, \& Pascarella, 1996; Smedley, Myers, \& Harrell, 1993), early retention strategies focused primarily on assisting minority students in becoming academically integrated at PWIs. However, Tinto noted that social integration influences persistence decisions for African American students as much as for Whites and that incongruence with social norms often makes it more difficult for African Americans at PWIs to "find and become a member of a supportive community within the college” (p. 74). Research indicates that African American students who do not establish supportive communities at PWIs often experience feelings of discomfort, social isolation, and stress, which can lead to student attrition (Feagin, Vera, \& Imani, 1996; Gossett, Cuyjet, \& Cockriel, 1998; Lang \& Ford 1992; Ponterotto, 1990; Sailes, 1993). 
Unlike White students, whose social integration occurs primarily through informal associations with peers, Tinto (1993) believed that social integration among students of color at PWIs was influenced more by formal forms of associations, such as involvement in student organizations. The importance of student organizations, especially cultural student organizations, to minority student retention at PWIs has been supported in the literature (DeSousa \& Kuh, 1996; Mallinckrodt \& Sedlacek, 1987; McClung, 1988). Murguia, Padilla, and Pavel (1991), in a qualitative study of Hispanic and Native American students, found that participation in ethnic organizations enabled students of color to scale down the larger campus environment by forming smaller "enclaves" (p. 436). They argued that once integrated into an ethnic enclave, students felt more comfortable exploring and integrating into the larger campus community. Similarly, Padilla, Trevino, Gonzalez, and Trevino (1997), using data collected in small focus groups with Hispanic, Asian American, Native American, and African American students, found that ethnic organizations enhanced their college experiences by allowing them to "retain and nurture a sense of ethnic identity on campus" (p. 134). They concluded that an important benefit of involvement in ethnic student organizations is to assist students of color in bridging the cultural gap between their home communities and PWIs.

These studies are valuable in identifying cultural student organizations as important to the social integration of students of color at PWIs. However, there is much that remains unknown regarding the conditions under which this involvement facilitates social integration. Research by Padilla et al. (1997) and Murguia et al. (1991) indicated that involvement provided students of color with cultural connections at PWIs, yet the 
researchers did not define how this connection occurs within the organizations or the characteristics of students for whom this connection is important. Additionally, prior research has not focused on the experiences of African Americans in cultural student organizations, which may be distinct from other minority students. The purpose of this study was to understand, from the perspectives of African American students, the conditions under which African American student organizations facilitate cultural connections and social integration at a PWI. Considering the importance of social integration to college student retention, this information is important to student affairs professionals at PWIs interested in supporting and retaining African American students.

\section{[METHODS] [A]}

Recently, college retention researchers have argued that quantitative measures of college student social integration have failed to identify the complexities involved in the social integration of minority students (Hurtado, 1997; Kuh \& Love, 2000). Rendon, Jalomo, and Nora (2000) have recommended that future research investigating the integration of minority students include qualitative methods that allow a definition of social integration to emerge from the students' perspectives. Therefore, to understand the impact of African American student organizations on social integration from the perspectives of students, qualitative methods using the constant comparative method of data collection and analysis were used in this study (Glaser \& Straus, 1967). Although the methods are similar to those used by Padilla et al. (1997), this study was designed to expand upon this earlier work by narrowing the sample to focus solely on African American students; expanding the numbers of African American students to gain a larger, more diverse range of perspectives (including the perspectives of freshmen); and by including individual 
follow-up interviews to expand upon themes raised during the group interviews (Glaser \& Straus) and to gain perspectives from participants who may have been uncomfortable sharing in the group interviews (Bogdan \& Biklen, 1998).

\section{[Sample] [B]}

A total of 88 African American students from a midsize (under 11,000 undergraduates), predominantly White (82\%) research institution located in the Northeastern United States participated in the study. The sample, which was approximately $45 \%$ male and 55\% female, consisted of 16 freshman, 39 sophomores, 18 juniors, and 15 seniors. To allow a wide array of perspectives to emerge, the sample included both actively involved students as well as those who reported little or no involvement in African American organizations.

Sixty-seven students volunteered to participate as part of their participation in a 6week academic enrichment program designed to serve students who were recommended by faculty and/or academic advisors as not living up to their college potential. This was defined as academic probation, suspension, or motivation to improve grades for acceptance into graduate school. GPAs for these students ranged from 0 to 3.0. To diversify the sample to include the perspectives of academically higher achieving students, flyers were posted around campus soliciting the participation of students who self-identified as "high achieving African American students.” This resulted in the addition of 20 students with GPAs ranging from a 2.5 to 3.93 .

\section{[Data Collection and Analysis] [B]}

Consistent with the prior research investigating cultural activities, small focus groups were used during data collection to obtain more real-world dialogue (Loftland \& Loftland, 1995). Similar to the study by Padilla et al. (1997), focus groups were originally 
designed to consist of 5 to 10 students and to last an hour. However, after the first group it become apparent that fewer students and longer sessions would enhance my ability to collect richer information. Therefore, focus groups were reduced to 2 to 6 students and interviews were conducted in periods of 1.5 to 2.5 hours.

Focus group interviews began open-ended to allow the participants to shape what was studied (Bogdan \& Biklen, 1998). Students were asked to begin by describing assets to their college experiences. This included asking them to give specific examples of their experiences in as much detail as possible. Later in the interviews they were also asked to describe any stumbling blocks or perceived liabilities to their success at college. Although participants raised a number of different themes when describing their assets and liabilities at college (e.g., faculty, academic counselors, and families), participation in African American student organizations emerged from students in every focus group. Consistent with the constant comparative method (Glaser \& Straus, 1967), individual follow-up interviews became more targeted to allow students to expand upon themes generated during the groups. This included asking them to clarify statements they made during the group interviews (e.g., What did you mean when you said you were more comfortable in African American groups?) or to check with members regarding hypotheses generated from the focus group interviews (e.g., Students seemed to indicate that it was difficult to get to know faculty out of the classroom unless they were members of a group. Would you agree with that?).

As Bogdan and Biklen (1998) recommended, an extensive audit trail was used to reduce potential biases in data analysis. This included detailed documentation of field notes and memos that addressed observer observations and reflections. In addition, I met 
weekly with a qualitative research group who monitored each other's work and pointed out potential biases and illogical conclusions from the data. To further reduce interpretation bias during data analysis, I actively sought negative case data, or instances that ran counter to the proposition that students shared a particular perspective regarding involvement (Becker \& Geer, 1960). Because the purpose was to reflect a broad African American student perspective regarding the impact of organizations on social integration, no attempt was made to separate the data by level of academic achievement in this study. I was assisted in this process by QUALOG (Shelly \& Sibert, 1992), a software application used to assist in managing and organizing textual.

\section{[RESULTS] [A]}

The African American student organizations that students discussed included academic honors groups, Greek societies, religious groups, political organizations, and student government. Although the purpose and mission of each type of organization differed, they all served similar purposes in facilitating cultural connections and social integration into the university. The most important reasons for valuing this membership were that the groups assisted them in establishing out-of-class connections with faculty, provided them opportunities to give back to other Blacks, and allowed them to feel comfortable by being around others perceived as like them. In addition, the groups helped expose and connect Black students from predominantly White home communities to African American culture.

\section{[Professional Connections] [B]}

One reason given for valuing involvement in African American student organizations was that the groups provided them with valuable out-of-class connections with African 
American faculty who were actively involved in the organizations. When asked if he had always had a strong relationship with faculty, this male explained how his involvement in a cultural organization was the key.

\{I would say being a member of an organization has helped because well, somebody explained it to me [that] it seems just a little strange if just a random person walks into somebody’s office [saying], “Hello, can I speak with them?” They might not give me the time of the day sometimes or whatever. But, if you're a member of an organization, they will probably give you the time of day sooner or later. It seems like being a part of something helps.

Although connecting with faculty out-of-class may be important to any student, several African American students commented that these relationships were especially important to them. This, in part, was due to the emphasis they placed on Blacks helping one another. Many students believed that the more Blacks they know in positions of power, the better their chances are to be aligned with someone who is able, and even obligated, to help them in the future. Participation in African American student organizations provided them an important means with which to establish these important out-of-class relationships with African American faculty.

\section{[Giving Back] [B]}

Another important way in which involvement in African American student organizations facilitated social integration was the opportunities the groups provided to give back to other Blacks. From helping orient new African American freshman to the campus, to raising money to educate Black children in Africa, community service targeted at helping 
other Blacks was an important part of the mission of most of these organizations. Feeling fortunate for their opportunity to further their education, many students spoke about giving back to other, less fortunate Blacks as important to feeling a part of the African American community on campus. This student explained why he believed that this type of service was important.

People in organizations are probably not just going here to get an education. They are willing to do something for somebody else so to speak. They are willing to bring their collective efforts together to help somebody else. Whether as a group to help somebody else in the organization or whether it is to help the other African Americans on the campus-like freshmen who might not know something. Just to spread the knowledge basically. Spread the knowledge they have to help somebody else.

Giving back also translated to promoting their race on campus and in the local community. Many of those most active in these groups viewed White faculty and peers as culturally insensitive or “ignorant” about African Americans. Members of African American student organizations dedicated considerable time educating others about their culture: sponsoring race dialogues, hosting prominent speakers on diversity, and organizing ethnic and cultural fairs on campus. Students believed that to improve things on campus for African American students, it was important to break down stereotypes through education and social activism. As one student explained, "We have to let people know basic stuff so they could learn and respect something about our culture. People just live in their own little bubbles.” Involvement in African American student organizations 
provided them with an organized outlet in which to work with other African Americans to serve the Black community. This service also appears to facilitate meaningful connections with other African Americans, therefore facilitating their social integration into the PWI.

\section{[Comfort] [B]}

The most strongly emphasized reason given by students for valuing participation in African American student organizations was what they described as the "comfort" the groups provided by allowing them to interact with other Blacks. Interestingly, most students said they chose to attend a PWI to diversify themselves through their social and academic interaction with students of other races and cultures. Their parents, teachers, and peers had emphasized that learning to work with a diverse group of people, especially White people, was crucial to succeeding in what they described as a "White world.” Yet becoming close to White peers was more difficult than some had anticipated. This was exacerbated by the fact that at the PWI, they were often the only Blacks in their classes, residence hall floors, or places of employment. When first arriving on campus, students described themselves as feeling overwhelmed by what seemed like a sea of White faces. This left many desperately seeking the comfort of associating with other Blacks.

For many students, African American student organizations provided the first opportunity to connect with peers whom they perceived as like them. This student, when asked how her friends felt about her spending so much time with her organization, explained the importance of the groups in establishing friendships at the university. 
Your minority friends are probably in your organization. I met a lot of my friends through the organizations so they are usually there. My classes do not have a lot of African Americans so to meet people, I met them through the organizations.

Because many of these groups were related to their interests or their academic majors, in addition to simply connecting with other people who looked like them, membership also provided the opportunity to connect with others who shared similar interests. For example, one of the more popular organizations was an African American gospel student choir. Here, students were able to connect with Blacks who not only shared an interest in singing, but who also shared religious beliefs. Other organizations, such as the Black engineering society or business club, provided the opportunity to meet other Black students from their majors with whom they might have not connected in classes.

Students also described their peers in the African American organizations as more friendly and open to them than the students in other student organizations that were comprised of mostly White students. Several students who first attempted to integrate into what they considered to be the "White" student organizations said they did not feel comfortable there. Because they were sensitive to being treated differently, these students were attuned to subtle signs of alienation or discomfort on the part of their White peers in the organizations. This student described perceiving what she called "the look" from White students when she entered a White student organization meeting.

Sometimes you just want to seem like a regular person and not feel like an outsider. Like you just sometimes get that look, like, "Why are you here?” 
They try to hide it and say hello but I can tell that look of surprise when I walk in sometimes.

Rather than battling through these perceived barriers within the mainstream student organizations, many students opted to invest their energies into the more comfortable environments of the African American student organizations.

Although the students in this study described these experiences often, the experiences were perceived as especially disturbing to students who came from all-Black areas who were interacting with White peers as a minority for the first time (as opposed to interacting with Whites in a predominantly Black environment). Those with prior experience interacting with White peers identified three main reasons for their ability to deal with these situations: (a) they were familiar with being the minority and were not on as high an "alert” for signs of alienation; (b) they had developed patience with White students, often attributing insensitive comments and actions to ignorance from lack of exposure; and (c) they were used to this type of friendly but distant relationships with White peers, some even preferring not to be close to White students. Additionally, they described themselves as having "realistic expectations" of their relationships with White students.

Yet being familiar with navigating the environment did not necessarily equate to being comfortable in it. Even those familiar with predominantly White educational settings described how much more welcoming other African American students were to them. They also emphasized how tiring it was being "the only one" and the necessity of having an all-Black environment in which they could feel more comfortable. 
African American student organizations also provided students with an outlet to discuss their experiences and frustrations of being a minority. This included discussing incidents at the university or in the community that they perceived as covertly racist, such as being followed around in a store by security. Students explained that their White peers were hesitant to recognize or empathize with them regarding these experiences. However, within the African American organizations, students were able to express these issues with others who could relate to them, understand their perceptions, and support them.

The opportunities the groups provided to meet people like themselves, to feel welcome, and to discuss their feelings of alienation and covert racism were all described as important to their definition of the comfort the students received from their involvement. However, the most central aspect of being comfortable was the opportunity the groups provided for the students to let their guards down and be themselves. As the minority, students said they felt the need to be guarded with their opinions and actions when they were around Whites. One reason for this was to avoid offending others. For example, two students shared incidents in which they had told race-related jokes that they believed to be innocent but that were taken as offensive by White students. Several others told of getting into heated political dialogues with White students who, they later realized, could not possibly understand their political views. Within the African American organizations, they felt free to tell jokes or express radical political views.

Being themselves also meant not having to constantly battle negative stereotypes of African Americans. As the only African Americans that many of their White peers encountered, they have imposed pressure on themselves not to perpetuate prejudicial views that White students may have about them. The most troubling of these stereotypes 
were Blacks being admitted only because of affirmative action initiatives and the perception that all Blacks were in gangs. There were other stereotypes, however, that, although they felt important not to perpetuate, were actually true. As a result, a dissonance between their true selves and the picture they wanted to present to their White peers arose. To battle this, many developed separate personas they presented to Whites, while reserving their true selves only for interactions with Blacks, which they referred to as code switching. This male student explained that code switching was a common phenomenon among Blacks.

I think that all Black people do it. I think it is just, like when you are a certain age to be able to turn different things on and off. I think that is like that across everyone but I think it is more so with Blacks; they learn how to do that between work and home and just Whites and Blacks. I think you learn how to speak differently or act differently or present yourself in a different manner. It's weird but it is something we just learn from day one. I think it just goes way back.

One example of code switching relates to dress. Several male students said that at home when socializing, they were comfortable wearing very baggy pants; loose shirts; lugs, which are a type of boot; and do-rags, a type of bandana on their heads. Although socializing at their PWI, however, particularly when interacting with White students, many of these students were careful not dress this way for fear of being perceived as a gangster. Instead, they have learned to either completely change their dress, or to alter it to conform more with their White peers. This student explains how he code switched by compromising his dress while at school. 
I sort of took a different route. Instead of getting rid of the boots, I hide them. I'll get baggy jeans but not too baggy. I dress the way I am right now, a little bit preppy with the hip-hop thing. I just make sure I don’t go too far.

Another example of code switching relates to verbal communication. Most students said they were most comfortable talking in what they described as "slang," or what could also be referred to as Ebonics (a term some of them considered offensive). Several examples of slang were given, such as saying something was "off the hook," meaning very cool or describing something as "straight," meaning okay or fine. These are words that most of their White peers did not understand so students refrained from using them. More importantly, they believed speaking slang was perceived as ignorant by Whites and perpetuated a stereotype that Blacks cannot speak proper English. Therefore, although they are more comfortable speaking slang in informal settings, they avoided using it when interacting with their White peers. Instead, students used proper English, or what they refer to as their "professional" or "business" language in the presence of Whites. A female student, who described herself as being fairly comfortable with Whites, gave an example of how she code switches with peers.

I find myself checking myself sometimes. Like if I am with a White girl I will say something like, “Oh, that guy is hot.” But if I am with Black girls I will be like, “Oh, he is fine! Yeah, he look real good!”

This constant process of checking and switching becomes stressful and can even cause confusion. One student remarked about her code switching around Whites, "After a while, I start stuttering because I am thinking too fast.” As another student explained, 
when she is with other African Americans, she feels she can let her guard down and speak in a way that is comfortable without fear of being seen as inferior.

I know how to speak proper English and most of the time I do but sometimes when I am around all Whites, like in an all-White class or something, I feel like I am thinking about it too hard. I am thinking about it more when I am noticeably in the minority.

Interacting with other Black students in African American organizations allowed them to feel as if the spotlight of being "the only one” was removed, albeit temporarily, and they could blend in. Free from the pressure to battle negative stereotypes constantly, or to justify that they belonged in these settings, they were comfortable to be themselves. This meant not having to think twice about telling a joke or holding back on what might be considered by Whites to be radical political views. It meant not having to educate peers all the time about their background and their history, or to explain everyday things like how they cared for their hair. Comfort also meant feeling free to wear do-rags on their heads without being seen as gangsters, or using slang without being viewed as ignorant. This student explained why she valued the respite her organizational involvement provided.

Because there are some things you don't have to worry about when you are around people who are like you. Like if we have nothing else in common, we share that experience of being the same color; that connects us in some kind of way. Because in my neighborhood, and everywhere else I go, it is mixed. But, in my educational settings, which is where I spend the majority of my time during the day, it's not like that. I know [in 
my all-Black organization] someone is not going to ask me about my hair or somebody is not going to say something they shouldn't have said that I have to break down and explain to them about da da da. Just feeling like you fit in for a moment. Like you are not looked at as the minority. For once, you are not different than everybody else. And that's important because it is one thing to be used to something but it gets tiring. Finally, African American student organizations provided students with a feeling of comfort by allowing them opportunities to socialize in ways that were comfortable and familiar. One of the most noticeable differences among themselves and White students was the difference between Black and White parties. Dancing to "good” music, meaning hip-hop, rhythm and blues, and reggae, was described as the emphasis at a typical Black party. On the contrary, the White parties tended to play rock music and focused on conversation rather than dancing. Additionally, they perceived White parties as centered around binge drinking. Although many of the African American students admitted drinking alcohol when socializing, it was usually consumed in moderation and before entering the Black parties. One reason for this was that unlike White parties, which were often held off-campus, Black parties often occurred in on-campus facilities that accommodated larger crowds. They perceived this as creating a safer atmosphere free from much of the obnoxious behavior they associated with binge drinking. Perceptions of bad music, no dancing and, as one student labeled it, “Animal House” antics, kept many students from ever attending a White party. Instead, these students frequented Black dance parties that were sponsored by various African American student organizations on campus. 


\section{[Exposure and Connection to Black Culture] [B]}

Although the importance of the cultural connections that the groups provided was a dominant theme in the data, not all African American students in the study placed such high value on the cultural connections. Further analysis of the data revealed that most of the students who discussed involvement in African American student organizations as an important component to their social integration into the university described themselves as coming from predominantly Black high schools. Others, who valued involvement for the same reasons but described their high schools as predominantly White, were quick to point out that they were bused to school and that their home environments were mostly Black. Although they were most comfortable with other Blacks, these students had learned to navigate a White educational environment.

However, examination of negative case data revealed that this was not the case for students who described their high schools and home communities as predominantly White. For these students, their most difficult adjustment in college resulted from interacting with other Black students for the first time. As with most college freshman, these students initially gravitated towards those with whom they were most comfortable. Because they were from White communities, they tended to share similar interests with White students rather than Blacks. This male explained why his first college friends were White.

I made friends with people who are more like me; who were like from the same types of neighborhoods as me; who listen to the same type of music as me; things like that. But, they weren’t necessarily African American 
and I found them [Whites] easier to get along with and more receptive to me. Again, I am not the usual African American.

One might think that because of this congruence with the norms of the majority at the institution, the transition to college might be easier for these students than for those from all-Black communities. Not so according to these students. Many described their unfamiliarity with Black culture as a major problem. Like many of their White peers, college was their first exposure to Black students. Yet unlike their White peers, they were expected by Black students not only to understand the Black culture, but to immerse themselves in it. This female student from a predominantly White home community describes a dilemma of being expected to attend a Black party.

I feel [comfortable with Blacks] now but up until last semester, I was scared of Black people. I was scared because I wasn’t used to hanging out with them. I went from high school, where I had mostly White friends - I was at a predominantly White environment there-and then I came here where everyone is White and it was the same thing. I had the same issue so when it came to like having to go to Black parties, I was like, I don't want to go. I can’t dance. I I don’t want some strange guy coming up behind me and being like, you know, I was scared.\} \{I didn't understand this. Was she afraid of being asked to dance and being embarrassed because she didn't do it well? Or was she afraid of being attacked in some way? Please edit for clarity. My thought was that she was scared because the experience was new to her. I checked the data aqain and did 


\section{not see any reference from her about her being fearful of being}

attacked. I was real scared of Black people at one point.

Although most comfortable with White students, completely avoiding the Black community was not seen as a viable option. Being seen socializing only with Whites, or passing the African American student organization rooms without saying, "What's up?" was frowned upon by their Black peers. This led to them being teased and called names such as “Oreo," meaning they were Black on the outside and White inside. Their unfamiliarity with Black culture and their perceptions of discrimination from being too White created an uncomfortable tension for these students when interacting with their Black peers.

However, for some students from predominantly White home communities, even these uncomfortable experiences with Black students became enriching. Seeing how out of touch they were with other Blacks, who "seemed so strong and confident of themselves and their Blackness,” created a need within some to expose themselves to and connect with the Black community. For three of the students who were from predominantly White environments, it was the African American student organizations that provided the important link they needed to connect with the Black community. For one student, it was his affiliation with an African American honors group that pulled him in to the Black community. Another student described being forced to attend the Black student government meetings by his girlfriend. Eventually, after being asked to help on some projects, he became president of the organization, which he later realized was instrumental in connecting him to the Black community. The female student who had 
been scared to attend Black parties described how her involvement in an all-Black sorority helped her.

So that kind of pulled me back in as well. That is one of the reasons I did it. Not just for the sisterhood but I was starting to feel really isolated and withdrawn, and it has been good. I have been happier this semester than I have been the prior year and a half here.

These three students perceived their participation in African American student organizations as enriching their college experiences by exposing them to and connecting them with Black culture for the first time.

\section{[DISCUSSION] [A]}

The results of this study support prior research regarding the importance of minority student organizations to students of color (Allen, 1988; DeSousa \& Kuh, 1996; McClung, 1988; Tatum, 1999; Taylor \& Howard-Hamilton, 1995). Consistent with the findings from Padilla et al. (1997) and Murguia et al. (1991), the groups were viewed by some students as a safe outlet in which to stay connected to their cultures. However, by extending the sample and focusing specifically on the perspectives of African American students attending a PWI, a more detailed account of how African American organizations facilitate cultural connections and social integration emerged.

Involvement in African American student organizations provided students an important means with which to connect with Black faculty outside the classroom, which has been found to be important to academic achievement and persistence (Pascarella \& Terenzini, 1991). A close relationship with faculty has been associated with better grades, higher levels of retention, and feelings of satisfaction with the university (Allen, 1988, 
1992; Kuh, Douglas, Lund, \& Ramin-\{Gyurnek,\} \{Gyunek in refs.\} 1994; Nettles \& Johnson, 1987; Nettles, Theony \& Gosman 1986; Sedlacek, 1987) and is important in facilitating both academic and social integration at college (Tinto, 1993). Establishing out-of-class relationships with faculty is also something that researchers have identified as being more difficult for African Americans attending PWIs than for White students at PWIs (Allen, Epp, \& Hanniff, 1991; Burrell \& Trombley, 1983; Flemming, 1984). Participation in African American organizations was viewed as one important way for Black students to overcome hurdles they may have perceived in establishing these important relationships.

The opportunities the groups provided to give back to the Black community was another important benefit of participating in African American student organizations. Although community service may be perceived as important to college students of all ethnicities, Black students, to varying degrees, perceived this as especially important for them. Involvement in student organizations allowed them to assist other Blacks through community service, through promoting their race on campus, and through uniting the Black community to make changes on campus. By allowing them opportunities to collectively give back to the Black community, community service in African American student organizations appears to play an important role in facilitating cultural connections and social integration into PWIs.

Most importantly, involvement in these organizations provided students an environment in which they could comfortably associate with other African Americans, or what Murguia et al. (1991) described as “ethnic enclaves” (p. 436). The results of this study expand our understanding of why ethnic enclaves are important to the social 
integration of African American students. First, students perceived other African Americans as friendlier and more accepting of them. They believed that White students were likely to negatively prejudge them and that only another African American could truly understand and relate to their experiences. Second, African American organizations allowed students to feel safe enough to let their guards down and to be themselves without the fear of offending others or of perpetuating prejudicial stereotypes. This included wearing baggy clothes, using slang, or talking about racial issues or politics. Last, the groups provided them opportunities to socialize in ways that were familiar, which included parties focused on music and dancing rather than conversation and drinking. These benefits were particularly salient to the social integration of African Americans who described their home schools or communities as predominantly Black. Feeling overwhelmed by what seemed like a sea of White faces, these students described themselves as desperately needing a respite from the White world to feel comfortable. This supports Tatum's (1999) assertion that PWIs concerned about attracting and retaining African Americans need to take seriously "the critical role that cultural space can play” (p. 80).

These results are consistent with Tinto's (1993) theory regarding the important role that student organizations can play in socially integrating Black students at PWIs. Many of the students who became active in African American student organizations perceived their views and norms as different from those of the White majority at the university. This was especially true for students from all-Black home communities. Although these students learned to navigate their educational environment, they described themselves as not being entirely comfortable in it. Constantly presenting a false 
persona necessitated finding a group they perceived as sharing norms, values, and intellectual views congruent with their own. The African American organizations provided them with this important cultural connection. By providing opportunities to connect with faculty out-of-class, to give back to other Blacks, and to socially interact with others perceived as like them, African American student organizations facilitated their social integration by providing them with valuable cultural connections.

However, the theory does not appear to be applicable when applied to African American students from predominantly White environments. Based on this theory, one would assume that these students would have experienced less difficulty transitioning to PWIs because their norms and values were more congruent with the White majority. This was not the case for those who attended this midsize PWI where there was a critical mass of African American students that allowed social segregation. Although this provided a buffer for those most comfortable around other Blacks, it alienated those who were accustomed to socializing with Whites by forcing them to choose between the two groups. Although they were more comfortable and familiar with the norms of the White majority, they felt alienated from other Blacks who saw them as turning their backs on their own. For these students, interacting with other Blacks for the first time was one of the most difficult aspects of their transitions to college.

Yet involvement in ethnic student organizations actually contributed to the social integration of some of these students who were initially uncomfortable around other Blacks by integrating them into the Black community for the first time. Tatum (1999) has found that this connection is important to the racial identity of all Black students, even those who identify most strongly with the majority culture. She has stated that without a 
shared identity with at least some subset of their racial group, these students are "at-risk for considerable social isolation” (p.70). Thus, although the groups did not provide a cultural bridge for facilitating the social integration of these students during their initial transitions to the PWIs, the potential exists for the groups to significantly impact their social integration and racial identity development once integrated into the majority culture of the university.

\section{[RECOMMENDATIONS AND CONCLUSIONS] [A]}

Clearly, more research is needed to understand the influence of ethnic student organizational involvement on African American students attending PWIs. However, the perspectives of the students in this study indicate that student affairs professionals at PWIs can assist in the process of socially integrating African American students from predominantly Black home communities by being pro-active in connecting them with Black student organizations. Student personnel who inform students of the various social, cultural, and academic African American student organizations early on provide one way to increase the potential for students to establish important cultural connections.

However, the role that African American organizations play in the lives of Black students is complex. Although all African American students who attend a PWI share some experiences, it is a mistake to consider them a homogenous group whose cultural needs can all be met through involvement in African American student organizations. Because their values, norms, and ideas were similar to the White majority, those from predominantly White home communities may not share the same need to connect with other Blacks to become socially integrated into the university. To effectively support 
these students, it is important for student affairs professionals to recognize and understand the differences among African American students.

These results indicate modifications may be necessary when applying Tinto’s (1993) theory of social integration to African American students from predominantly White home communities who attend PWIs. Although their values, norms, and ideas may be highly congruent with those of the institution, their comfort with White students and their unfamiliarity with Black culture may cause additional barriers to becoming socially integrated into the university.

Future research should examine the impact of African American student organizations on social integration at other PWIs. In addition, more research is needed to understand the role that ethnic organizations can play in the racial identity development of African American students from both predominantly Black and White home communities. Finally, although it is important to recognize the important role that African American student organizations can play in providing cultural connections and facilitating social integration, research targeted at understanding how this involvement affects academic integration would enhance the ability of student affairs professionals to more effectively support these students at PWIs. 


\section{REFERENCES}

Allen, W. R. (1988). The education of Black students on White college campuses: What quality the experiences? In M. Nettles (Ed.), Toward Black undergraduate student equality in American higher education (pp. 57-86). Albany: State University of New York Press.

Allen, W. R. (1992). The color of success: African-American college student outcomes at predominantly White and historically Black public colleges and universities. Harvard Educational Review, 62(1), 26-44.

Allen, W.R., Epp, E.G., \& Haniff, N.Z. (1991). College in Black and White: African American student in predominately White and in historically Black public universities. Albany: State University of New York Press.

Astin, A. W. (1996). Degree attainment rates at American colleges and universities: Effects of race, gender, and institutional type. Los Angeles, CA: Higher Education Research Institute, University of California. (Eric Document Reproduction Service No. ED 400 749).

Becker, H. S., \& Geer, B. (1960). Participant observation: The analysis of qualitative field data. In R. N. Adams \& J. J. Preiss (Eds.), Human organization research: Field relations and techniques (pp. 267-289). Homewood, IL: Dorsey Press.

Benson, M.E. (1996). NCAA Division I Graduation-Rates Report, 1996. Graduation-Rates Data (1986-87, 1987-88, 1988-89, and 1989-90 Entering Classes), Undergraduate Enrollment Data (Fall 1995), [and] Student-Athlete Admissions Data (1992-1995 Entering Freshmen 
Classes). (Report No. NCAA- 1097-6-96). Overland Park, KS: National Collegiate Athletic Association. (Eric Document Reproduction Service No. ED407911).

Bogdan, R. C., \& Biklen, S. K. (1998). Qualitative research in education. Needham Heights, MA: Allyn \& Bacon.

Boyle, T. P. (1989). An examination of Tinto's model of retention in higher education. NASPA Journal, 26(4), 288-294.

Burrell, L.F. \& Trombley, T.B. (1983). Academic advising with minority students on predominantly White campuses. Journal of College Student Personnel. 121-126.

Cabrera, A. F., Nora, A., Terenzini, P. T., Pascarella, E., \& Hagedorn, L. S. (1999). Campus racial climate and the adjustment of students to college. Journal of Higher Education, 70(2), 134-160.

DeSousa, D. J., \& Kuh, G. D. (1996). Does institutional racial composition make a difference in what Black students gain from college? Journal of College Student Development, 37, 259-267.

Donovan, R. (1984). Path analysis of a theoretical model of persistence in higher education among low-income Black youth. Research in Higher Education, 21, 243-252.

Feagin, J. R., Vera, H., \& Imani, N. (1996). The agony of education: Black students at White colleges and universities. New York: Routledge.

Flemming, J. (1984). Blacks in college: A comparative study of students' success in Black and White institutions. San Francisco: Jossey-Bass. 
Gillespie, M., \& Noble, J. (1992). Factors affecting student persistence: A longitudinal study (ACT Research Report No. 92-4). Iowa City, IA: American College Testing Program.

Glaser, B., \& Straus, A. (1967). The discovery of grounded theory: Strategies for qualitative research. New York: Aldine.

Gossett, B. J., Cuyjet, M. J., \& Cockriel, I. (1998). African Americans’ perception of marginality in the campus culture. College Student Journal, 32, 22-32.

Hurtado, A. (1997). Understanding multiple group identities: Inserting women in cultural transformations. Journal of Social Issues, 53(2), 299-328.

Kuh, G. D., Douglas, K. B., Lund, J. P., \& Ramin-\{Gyunek,\} \{Gyurnek on p. 22.\} J. (1994). Student learning outside the classroom: Transcending artificial boundaries. Washington, DC: George Washington University.

Kuh, G. D., \& Love, P. G. (2000). A cultural perspective on student departure. In J.M. Braxton (Ed.), Reworking the student departure puzzle (pp. 196-213). Nashville, TN: Vanderbilt University Press.

Lang, M., \& Ford, C. A. (1992). Strategies for retaining minority students in higher education. Springfield, IL: Charles C. Thomas.

\{Lofland, J., \& Lofland, L. H. (1995). Analyzing social settings: A guide to qualitative observation analysis. Belmont, CA: Wadsworth.

Loo, C. M., \& Rolison, G. (1986). Alienation of ethnic minority students at predominately White institutions. Journal of Higher Education, 57(1), 5877. 
Mallinckrodt, B., \& Sedlacek, W. E., (1987). Student retention and the use of campus facilities by race. National Association of Student Personnel Administrators, 24(3), 28-32.

McClung, J. J. (1988). A Study to identify factors that contribute to Black student withdrawal at Clemson University. Clemson, SC: Clemson University. (Eric Document Reproduction Service No. ED 300483.

Murguia, E., Padilla, R. V., \& Pavel, M. (1991). Ethnicity and the concept of social integration in Tinto’s model of institutional departure. Journal of College Student Development, 32, 433-439.

Nettles, M. T., \& Johnson, J. R. (1987). Race, sex, and other factors as determinants of college students’ socialization. \{Journal of College Student Personnel, 28, 513524. $\}$

Nettles, M. T., Thoeny, R. A., \& Gosman, E. J. (1986). Comparative and predictive analyses of Black and White students' college achievement and experiences. Journal of Higher Education, 57(3), 289-317.

Nora, A., Cabrera, A. F., \& Pascarella, E. T. (1996). Different impacts of academic and social experiences. Research in Higher Education, 37(4), 427-451.

Padilla, R. V., Trevino, J., Gonzalez, K., \& Trevino, J. (1997). Developing local models of minority student success. Journal of College Student Development, 38, 125-138.

Pascarella E. T., \& Terenzini, P. (1991) How college affects students. San Francisco: Jossey-Bass 
Patterson Research Institute College Fund/UNCF. (1997). The African American education data book: Higher and adult education. Washington, DC: \{Please include publisher. Review Example 24 on pp. 248-249.\}

\{Ponterotto, J. G. (1990). Racial/ethnic minority and women students in higher education: A status report. In (Ed.) or (Eds.), (New Directions for Student Services No. 52, pp. 4559). San Francisco: Jossey-Bass.\} \{We treat these as chapters in edited books. Please fill in the blanks with the editor's name and the title of the edited work.\}

Rendon, L. I., Jalomo, R. E., \& Nora, A. (2000). Theoretical considerations in the study of minority student retention in higher education. In J. M. Braxton (Ed.), Reworking the student departure puzzle (p. 127-153). Nashville, TN: Vanderbilt University Press.

Sailes, G. A. (1993). An investigation of Black student attrition at a large, predominantly White, Midwestern university. The Western Journal of Black Studies, 17, 179-182.

Sedlacek, W. E. (1987). Black students on White campuses: 20 years of research. Journal of College Student Personnel, 485-495.

\{Shelly, A., \& Sibert, E. (1992). Qualitative analysis: A cyclical process assisted by computer. In G. L. Hueber (Ed.), Qualatative Analyse: Computereinsatz in Der Sozialforschung (pp. 71-114).\} \{Please review and follow Example 31 or 32 on p. 251 of the APA style guide.\} \{Munich, Vienna:\} \{If the publisher's location is Munich, please 


\section{replace "Vienna" with "Germany." If the location is Vienna, no} country is needed.\} R. Oldenbourg Verlag.

Smedley, B. D., Myers, H. F., \& Harrell, S. P. (1993). Minority-status stresses and the college adjustment of ethnic minority freshman. Journal of Higher Education, 64, 434-452.

Spady, W. G. (1970). Dropouts from higher education: An interdisciplinary review and synthesis. Interchange, 1, 64-85.

Tatum, B. D. (1999). Why are all the Black kids sitting together in the cafeteria? And other conversations about race. New York: Basic Books.

Taylor, C. M., \& Howard-Hamilton, M. F. (1995). Student involvement and racial identity attitudes among African American males. Journal of College Student Development, 36, 330-336.

Tinto, V. (1993). Leaving college: Rethinking the causes and cures of student attrition. Chicago: The University of Chicago Press. 